Edward, D. G. FF. \& Fitzgerald, W. A. (1951). J. gen. Microbiol. 5, 576-586.

\title{
Cholesterol in the Growth of Organisms of the Pleuropneumonia Group
}

\author{
By D. G. FF. EDWARD AND W. A. FITZGERALD \\ The Wellcome Veterinary Research Station, Frant, Sussex, and \\ the Wellcome Research Laboratories, Beckenham, Kent
}

\begin{abstract}
SUMMARY: Representative strains of the pleuropneumonia group, originally isolated from animals, grew well on a basal medium containing infusion broth, peptone, yeast extract and agar when this was further enriched with horse serum. The serum could be replaced by an ethereal extract of egg-yolk and fractionation of this suggested that cholesterol might be the active substance promoting growth. Growth was obtained when cholesterol $(0.01 \mathrm{mg}$. $/ \mathrm{ml}$.) was added to the basal medium, together with starch or bovine albumin. Addition of the acetone-insoluble fraction of egg-yolk with cholesterol gave better results, growth of six of the eight strains tested being equal to that on serum agar; the lecithin and kephalin fractions after purification were less effective. No growth was obtained when starch, bovine albumin or the acetone-insoluble lipid was added to the medium without cholesterol. Cholestanol and stigmasterol were as effective as cholesterol in promoting growth. Oleic acid in high concentrations $(>0.05 \mathrm{mg} . / \mathrm{ml}$.) inhibited growth. Both lipid and protein fractions of serum appeared to be concerned in its ability to promote growth.
\end{abstract}

Pleuropneumonia-like organisms, whose smallest viable forms have been shown by ultra-filtration studies to measure $c .150-200 \mathrm{~m} \mu$., are the smallest microorganisms which can be cultivated on cell-free media. Their nutritional requirements are therefore of particular interest. Moreover, a study of their metabolism may assist in establishing the relationship of this group of organisms to the ordinary bacteria. Although certain saprophytic members of the group can be cultivated easily on relatively simple media (Laidlaw \& Elford, 1936), conditions for the growth of strains isolated from animals, including all the pathogens, are more exacting. In particular, the latter strains differ from the saprophytic ones in needing media further enriched by materials to be found in serum and ascitic fluid. The necessity to add a complex material such as serum complicates the investigation of essential growth requirements and the development of a defined medium.

Not all animal sera are equally effective for growing every strain (Sabin, 1941; Edward, 1950). Of those tested horse serum and human serum (or ascitic fluid) have proved most satisfactory and are commonly used. With rabbit serum some strains grow well; others grow poorly or not at all. It is perhaps possible that organisms of this group exist which cannot be isolated on media at present in use because neither horse nor human serum provides adequate enrichment.

In undertaking a study of growth requirements it was therefore considered desirable to investigate first the material in serum which was essential for growth. The earliest experiments were based on the belief that it was serum protein which was needed (Sabin, 1941 ; Edward, 1950). No progress was made, 
however, in attempts to isolate a growth factor by fractionation of the serum protein. The finding that a precipitate, which developed as a result of the growth of certain strains in media enriched with horse serum, consisted of calcium soaps, drew attention to the importance of lipids and thereby suggested a new approach. It was found that pleuropneumonia-like organisms would multiply on a medium in which serum was replaced by an ethereal extract of egg-yolk. This observation led to the work described here.

\section{METHODS}

Details are given in Table 1 of the eight strains, each believed to belong to a different species of the pleuropneumonia group, which were used in the investigation. They were maintained as surface cultures by twice weekly subculture on horse serum agar. The medium consisted of $70 \%(\mathrm{v} / \mathrm{v})$ agar base prepared from ox heart infusion broth with the addition of $1 \%(\mathrm{w} / \mathrm{v})$ peptone, $10 \%(\mathrm{v} / \mathrm{v})$ yeast extract $(50 \mathrm{mg}$. Oxoid $/ \mathrm{ml}$.$) and 20 \%(\mathrm{v} / \mathrm{v})$ horse serum; the reaction was adjusted finally to $\mathrm{pH} \mathbf{8 \cdot 0}$. Thallium acetate and penicillin were incorporated in the medium to prevent the growth of contaminating bacteria (Edward, 1947). In the experimental media the serum was replaced by saline suspensions of the materials to be tested. The volumes of the suspensions were so adjusted, that, whether one or more was added, the total volume of the additions was $20 \%$ of the final volume of the complete medium.

Plates of experimental media were inoculated by cutting out a small piece of agar bearing growth from a 3-day culture on horse serum medium. This piece was inverted over the plate to be inoculated, smeared across it and afterwards discarded. It was usual to inoculate four strains on the same plate by dividing the plate into quarters. Cultures were examined after 3 and 6 days' incubation at $37^{\circ}$ in a moist atmosphere. The degree of growth was assessed by examination with a dissecting microscope (magnification $\times 10$ ), using slightly oblique transmitted light. When the medium was too opaque for the growth to be seen in this way, a hand-lens was used.

To prepare an ethereal extract of egg-yolk, the yolks of three eggs, which had been separated from the egg-white and washed with saline, were emulsified in $50 \mathrm{ml}$. of saline. An equal volume of ether was added, the mixture well shaken, centrifuged and the ethereal layer removed. This process was carried out from three to five times and the pooled ethereal extracts, after filtration through paper, were distilled at reduced pressure to remove ether and traces of water. The final product was emulsified in saline. Fractionation of the ethereal extract was carried out by distilling off ether until the total volume was c. $100 \mathrm{ml}$. This solution was then pipetted slowly into twice its volume of cold acetone. After standing at $4^{\circ}$ for $60 \mathrm{~min}$. the precipitate of acetone-insoluble material was collected by centrifugation. After washing twice with acetone the precipitate was dried in a vacuum desiccator over sulphuric acid. The supernatant fluid containing the acetone-soluble fraction, after filtration through paper, was evaporated to an oily paste by distillation. Emulsions in saline, suitable for addition to the medium, were made by using a Ten Broeck grinder. Other fatty substances examined during the investigation were emulsified in 
a similar manner; occasionally gum acacia was used to increase the stability of the emulsion.

To prepare finely dispersed aqueous suspensions of cholesterol, $100 \mathrm{mg}$. were dissolved in $2 \mathrm{ml}$. of warm ethanol. This solution was ejected into $100 \mathrm{ml}$. of distilled water at $c .80^{\circ}$, using a Pasteur pipette drawn out to a fine capillary. It was essential to introduce all the solution with the point of the pipette below the surface of the water. Crystallization from the ethanolic solution was prevented by keeping both it and the pipette warm. Many excellent suspensions with practically all the cholesterol in a finely dispersed state were prepared in this manner, but the method was not always successful, and several attempts were sometimes necessary before a satisfactory suspension was obtained. It was important to use freshly distilled water of neutral reaction; suspensions rapidly flocculated with a slight change in reaction to the acid side. Flocculation did not occur when the suspension was added to the basal medium, Suspensions of cholesteryl esters and of other sterols were prepared in the same way.

Table 1. Details of strains used for the investigation

\begin{tabular}{ll} 
Strain & \multicolumn{1}{c}{ Details } \\
PP3278 & A strain of Asterococcus bovis* \\
L4 & Isolated from rats; produced arthritis and abscesses* \\
M46 & Isolated from mice suffering from infectious catarrh* \\
B2 & Isolated from the bovine genital tract; a P strain* \\
H17 & Isolated from the human genital tract* \\
C27 & Isolated from a dog; a $\gamma$-strain $\dagger$ \\
C48 & Isolated from a dog; an $\alpha$-strain $\dagger$ \\
C55 & Isolated from a dog; a $\beta$-strain $\dagger$ \\
&
\end{tabular}

$\uparrow$ For details of the isolation and behaviour of these strains, see Edward \& Fitzgerald (1951).

\section{RESULTS}

\section{Growth with lipid fractions of egg-yolk}

Each of the eight representative strains was subcultured on the basal medium to which had been added varying amounts of a saline suspension of egg-yolk. All except one strain grew well with each of the concentrations of yolk tested $(5-0.25 \%) ; 0.25 \%(v / v)$ appeared to be about the lowest effective concentration. The strain of Asterococcus bovis grew poorly over the whole range of concentrations. When an ethereal extract of yolk, resuspended in saline to the original volume of the yolk, was added instead of whole yolk, six of seven strains tested grew well with concentrations between 5 and $1 \%(\mathrm{v} / \mathrm{v})$, with $0.5 \%(\mathrm{v} / \mathrm{v})$ growth was poor. There was only a trace of growth of $\boldsymbol{A}$. bovis.

An ethereal extract of yolk was separated into two fractions by precipitation with acetone. The acetone-insoluble fraction (subsequently referred to as acetone-insoluble lipid AIL) was tested without further purification for its ability to promote growth. In a number of experiments no growth of any strain was obtained by adding amounts between 4 and $0.4 \mathrm{mg} . / \mathrm{ml}$. to the basal medium. All the strains, except $A$. bovis, grew when the acetone-soluble fraction, resuspended in saline to the original volume of the yolk, was added at 
concentrations between 5 and $1 \%(v / v)$. The growth, however, of some strains was poor and appeared to be improved by adding AIL $(1 \mathrm{mg} . / \mathrm{ml}$.) in addition to the acetone-soluble fraction.

Some of the acetone-soluble fraction was hydrolysed with ethanolic $\mathbf{K O H}$ and the unsaponifiable material extracted with ether. Growth of strains C27 and $L 4$ was obtained when the unsaponifiable material was incorporated in the medium together with $1 \%$ soluble starch. On media containing the unsaponifiable material and no starch, strain L4 grew, but strain C 27 did not. Thus the factor promoting growth appeared to be contained in the unsaponifiable part of the acetone-soluble fraction of egg-yolk. Since this largely consisted of sterols, especially cholesterol, experiments were continued to discover whether a purified preparation of cholesterol would promote growth.

\section{Promotion of growth by cholesterol}

Numerous attempts were made to grow the strains in the basal medium (without serum) by adding cholesterol $(0 \cdot 1 \mathrm{mg} . / \mathrm{ml}$.) as a finely dispersed aqueous suspension, prepared as described above. In a few experiments growth of certain strains was obtained. Strain C27 appeared to be the easiest to grow, but in only four out of twenty-two experiments was growth good or moderate. More often growth was only noted on that part of the plate which had been inoculated most heavily; it had probably been assisted by substances carried over in the inoculum. Even when good growth was obtained the colonial appearances were atypical; the outlines of the colonies were irregular and central spots, so typical a feature of pleuropneumonia-like organisms, were absent. Improved results were obtained by incorporating $1 \%$ soluble starch with the cholesterol in the medium. In five out of seven experiments strain C27 grew satisfactorily. Growth of certain other strains was obtained in some, but not in all experiments. Growth tended to be slow in appearing and the colonies were atypical. $A$. bovis failed to grow with cholesterol alone or with cholesterol and starch.

The beneficial effect of starch in some bacteriological media is now believed to be partly due to its ability to bind fatty acids. The effect of adding bovine albumin, fraction $\mathrm{V}$ (Amour Laboratories), also used in media because of its ability to bind fatty acids (Davis \& Dubos, 1947), was tried. On a medium containing cholesterol and $5 \mathrm{mg}$. bovine albumin $/ \mathrm{ml}$., strain C27 grew at least moderately well in fourteen out of fifteen tests. Strain L 4 grew equally as well, and nearly as good results were obtained with strains $\mathrm{B} 2, \mathrm{H} 17$ and M46. The colonial appearances were typical, but it was noted that growth was often slower in appearing than on horse serum agar. $A$. bovis grew satisfactorily on this medium in only one of nineteen tests; growth of strains C48 and C55 also was poor and occurred in only a minority of tests.

In the experiments with fractions obtained from egg-yolk by acetone precipitation it had been noted that, although growth was obtained with the acetone-soluble fraction, it was improved when the acetone-insoluble fraction (AIL) was present in the medium in addition. When AIL was incorporated in the basal medium with cholesterol in concentrations from 4 to $0.4 \mathrm{mg}$. $/ \mathrm{ml}$, 
excellent growth of strain $\mathrm{C27}$ was obtained in every one of fifteen tests. Strains L4, B 2, H17, M46 and C55 also grew as well as they did on horse serum agar; there was no delay in the appearance of growth and the colonies were typical. This medium, however, was not satisfactory for the growth of A. bovis and strain C48. In three tests, made with the same batch of AIL, $A$. bovis grew moderately well, but eleven other experiments were negative.

When either starch, bovine albumin, AIL or a mixture of bovine albumin and AIL was added to the basal medium without cholesterol, no growth of any strain was obtained. It would therefore appear that cholesterol (or some derivative of it; see below, p. 582) was essential for growth.

Certain strains, such as strain $\mathbf{C 2 7}$, will not grow satisfactorily on media enriched with rabbit serum instead of horse serum unless they have first been subjected to a process of gradual adaptation by repeated subculture over many weeks. It was found that strain $\mathrm{C} 27$ grew well without previous adaptation on agar plates and in broth enriched with rabbit serum when cholesterol $(0.1 \mathrm{mg} . / \mathrm{ml}$.) was also added. This finding proved useful when rabbit serum broth cultures were required for injecting rabbits to prepare antisera (Edward \& Fitzgerald, 1951).

\section{The concentrations of cholesterol and AIL necessary for growth}

The least amount of cholesterol necessary to give good growth was determined using two different concentrations of AIL, 4 and $0 \cdot 4 \mathrm{mg} . / \mathrm{ml}$. All the strains grew well with $0.1 \mathrm{mg}$. cholesterol $/ \mathrm{ml}$; ; with $0.03 \mathrm{mg} . / \mathrm{ml}$. growth was not so good (Table 2). Two strains, C27 and C55, grew better with $0.4 \mathrm{mg}$. $\mathrm{AIL} / \mathrm{ml}$. than with $4 \mathrm{mg}$. $/ \mathrm{ml}$; ; with the larger amount of AIL a higher concentration of cholesterol was required. Strain M46 did not grow on the media containing 0.4 mg. AIL $/ \mathrm{ml}$. Using the higher concentration of AIL good growth of this strain was obtained with $0 \cdot 1 \mathrm{mg}$. cholesterol $/ \mathrm{ml}$.; with twice this amount of cholesterol growth was less good.

Table 2. Effects of varying amounts of cholesterol in media containing two different concentrations of acetone-insoluble lipid $(A I L) 4.0$ or $0.4 \mathrm{mg} . / \mathrm{ml}$.

\begin{tabular}{|c|c|c|c|c|c|c|c|c|c|c|}
\hline \multirow{2}{*}{$\begin{array}{l}\text { Concen- } \\
\text { tration of } \\
\text { cholesterol } \\
(\mathrm{mg} . / \mathrm{ml} \text { ) }\end{array}$} & \multicolumn{2}{|c|}{ Strain C27 } & \multicolumn{2}{|c|}{ Strain L 4} & \multicolumn{2}{|c|}{ Strain B2 } & \multicolumn{2}{|c|}{ Strain M46 } & \multicolumn{2}{|c|}{ Strain C 55} \\
\hline & 4 & $0 \cdot 4$ & 4 & $0 \cdot 4$ & 4 & $0 \cdot 4$ & 4 & $0 \cdot 4$ & 4 & 0.4 \\
\hline 0.5 & + & + & + & \pm & + & + & \pm & - & + & + \\
\hline $0 \cdot 2$ & \pm & + & + & + & + & + & \pm & - & \pm & + \\
\hline $0 \cdot 1$ & \pm & + & + & + & + & + & + & - & tr. & + \\
\hline 0.03 & - & \pm & + & + & tr. & tr. & - & - & - & \pm \\
\hline 0.01 & - & - & tr. & \pm & - & - & - & - & - & - \\
\hline
\end{tabular}

+ represents good growth. \pm represents poor growth. tr. represents a trace of growth only. - represents no growth.

In a later experiment, in which $0.8 \mathrm{mg}$. of another preparation of $\mathrm{AIL} / \mathrm{ml}$. was incorporated in the medium, $0.01 \mathrm{mg}$. cholesterol $/ \mathrm{ml}$. was found to be the least amount giving good growth of strain C27. Different suspensions of 
cholesterol were used in the two experiments, and the difference in the results may possibly have been due to differences in the amount of cholesterol in a finely dispersed state. It was not always possible to obtain suspensions of the same quality. In two other experiments $0.01 \mathrm{mg}$. cholesterol $/ \mathrm{ml}$. was the least amount giving good growth, when incorporated in the medium with bovine albumin ( $5 \mathrm{mg} \cdot / \mathrm{ml}$.).

Varying amounts of AIL were added to media containing $0 \cdot 1 \mathrm{mg}$. cholesterol/ ml. Strains C27, L4 and C55 grew with each of the concentrations of AIL tested, from 2 to $\mathbf{0 . 2} \mathrm{mg} . / \mathrm{ml}$. (Table 3). Strains B2 and H17 only grew with the largest amount ( $2 \mathrm{mg} . / \mathrm{ml}$.).

Table 3. Effect of varying amounts of acetone-insoluble lipid (AIL) in media Added containing $0 \cdot 1 \mathrm{mg}$. cholesterol/ml.

$\begin{array}{cccccc}\begin{array}{c}\text { AIL } \\ \text { AIL./ml.) }\end{array} & \text { Strain C27 } & \text { Strain L4 } & \text { Strain B2 } & \text { Strain H17 } & \text { Strain C55 } \\ \mathbf{2} & + & + & + & + & + \\ \mathbf{0} \cdot 8 & + & + & \pm & - & + \\ \mathbf{0 \cdot 4} & + & + & - & - & + \\ \mathbf{0 \cdot 2} & + & + & - & - & +\end{array}$

Symbols as in Table 2.

These experiments suggested that optimum growth was obtained when there was a balance between the proportions of cholesterol and AIL in the medium. Strains appeared to vary in the amount of AIL which was necessary for their growth. There was also a suggestion from these and other experiments that growth was inhibited or impaired when cholesterol or other lipid fractions were added in amounts greater than those giving optimal growth.

\section{Attempts to identify the factor in AIL assisting growth}

Although growth of most strains was obtained on media containing cholesterol and bovine albumin, results were not consistent and growth appeared comparatively slowly. On media in which cholesterol was incorporated with AIL, consistently good growth equal to that on media enriched with horse serum was obtained with all except two strains. Therefore attempts were made to identify the material in AIL which was responsible for full development of growth.

The insoluble fraction obtained from egg-yolk by precipitation with acetone (AIL) was purified by reprecipitation three times with acetone; it still gave good growth in media containing cholesterol. A preparation of AIL was fractionated by precipitating a chloroform solution with ethanol. The precipitate (kephalin fraction), tested for activity without further purification, gave as good growth on media containing cholesterol as did the original AIL. The lecithin fraction, obtained by precipitating the alcohol-soluble portion with acetone, gave only a moderate growth which was slow in appearing. Purified preparations of lecithin and kephalin, prepared by Dr S. Wilkinson of the Chemical Division, The Wellcome Research Laboratories, when incorporated 
in the medium with cholesterol, gave only moderate and slow growth. There was no growth when either preparation was added to the medium without cholesterol. Similar results were obtained with two other purified preparations of lecithin and kephalin. The other fractions obtained during the process of purification were also tested for activity. Activity did not seem to reside in any one particular fraction, but it appeared from this and other experiments that, once a separation of AIL into lecithin and kephalin fractions had been made by ethanol precipitation, activity was lost during the subsequent repeated steps of acetone precipitation used in purification. An impure preparation of sphingomyelin was inactive.

Attention must be drawn to certain technical difficulties encountered in this part of the investigation. In order to determine the presence of growth and to assess its development accurately, it was necessary to observe cultures with a dissecting microscope, using transmitted light. This was only possible when the medium was relatively translucent. Many of the lipid fractions tested were difficult to incorporate in the medium as finely dispersed suspensions. The media were often opaque, contained numerous oily globules and had an uneven surface. Under these conditions it was difficult to assess the amount of growth.

It was concluded that in media containing cholesterol the acetone-insoluble material from egg-yolk assisted growth, so that it was as good as on serum media and was better than on media containing cholesterol + albumin. Lecithin and kephalin fractions, purified by acetone-precipitation, did not give such good results, growth being no better than with cholesterol and albumin.

\section{Effect of cholesterol esters and of other sterols}

On media containing albumin or AIL equally good growth was obtained with three different preparations of cholesterol. One preparation had a purity exceeding $99 \%$. It must, however, be pointed out that there are always present in aqueous suspensions of cholesterol hydroxylated and oxygenated derivatives, such as 7-hydroxycholesterol (Haslewood, 1944). Strains C 27 and L 4 grew moderately well on media containing starch and cholesteryl hydrogen phthalate $(0.05 \mathrm{mg} . / \mathrm{ml}$.), an ester which is slightly soluble in water; there was no growth when this ester was added to the medium without starch. No growth was obtained with cholesteryl acetate, cholesteryl stearate or cholesteryl oleate, tested at concentrations of $0.3,0.1$ and $0.03 \mathrm{mg} . / \mathrm{ml}$., when added to the medium alone, or with starch, bovine albumin or AIL.

Four other sterols, very kindly provided by Prof. G. A. D. Haslewood, were tested for ability to promote growth. Growth, equal to that given by cholesterol, was obtained with cholestanol or stigmasterol incorporated in the medium with bovine albumin or AIL ; the minimum active concentrations were approximately the same as for cholesterol. Under the same conditions no growth was obtained with ergosterol and coprosterol, but this may have been due to a failure to obtain suitably dispersed suspensions. When an aqueous suspension of coprosterol was added to the medium it appeared to flocculate and crystallize out. The technique, which had been used for the other sterols, was not successful for obtaining a finely dispersed suspension of ergosterol. 


\section{Effect of protein and lipid fractions of serum in promoting growth}

Since growth was obtained by adding ether-soluble fractions of egg-yolk to the medium, it seemed possible that the ability of serum to promote growth might be due to its lipid constituents. The method of Hartley (1925) was used to obtain a preparation of serum protein freed from lipids. When this was added to the basal medium alone there was no growth of the strain tested. There was also no growth on a medium in which were incorporated the lipids extracted from the serum in the preparation of the lipid-free protein. However, when the lipids and the lipid-free protein were added together there was a moderately good growth of strain $\mathrm{C} 27$. Some growth was obtained by adding to the medium a mixture of serum lipids and AIL (5 mg./ml.), but there was no growth on media to which had been added cholesterol $(0 \cdot 1 \mathrm{mg} . / \mathrm{ml}$.) and serum lipids. Good growth occurred on media in which the serum lipids had been incorporated together with bovine albumin. These findings suggest that both protein and lipid fractions of serum are concerned in its ability to promote growth of organisms of the pleuropneumonia group.

Equally good growth was obtained on media containing cholesterol and a preparation of serum proteins freed from lipids by Hartley's method, as on media containing cholesterol and bovine albumin. The effect of this fraction of bovine albumin would thus appear to be due to the protein itself and not to any lipids possibly associated with it.

\section{Inhibition by oleic acid}

Recently considerable attention has been paid to the effects of fatty acids, particularly unsaturated acids such as oleic acid, on the growth of bacteria. Excessive concentrations have been found to be inhibitory, some organisms being particularly sensitive, whereas for other organisms small amounts of certain fatty acids are essential for growth (Pollock, 1949). Since the growth of pleuropneumonia-like organisms on media containing cholesterol was favoured by substances, such as starch and albumin, which bind fatty acids, the action of oleic acid on organisms of the pleuropneumonia group was studied. When varying amounts of oleic acid were added to media enriched with $5 \%$ horse serum $0.1 \mathrm{mg}$. oleic acid $/ \mathrm{ml}$. inhibited all strains, though normal growth occurred with half that amount. In media containing $2.5 \%$ horse serum $0.05 \mathrm{mg}$. oleic acid $/ \mathrm{ml}$. was inhibitory. Amounts of oleic acid exceeding $0.05 \mathrm{mg} . / \mathrm{ml}$. were also inhibitory in media containing cholesterol and bovine albumin instead of serum.

Growth of $A$. bovis and strain $\mathbf{C} 48$ on media containing $5 \%$ horse serum appeared in two experiments to be improved by adding small non-inhibitory amounts of oleic acid. This was not confirmed in subsequent experiments, and it was not possible to obtain regularly good growth of these strains on media containing cholesterol and albumin, or cholesterol and AIL by adding varying amounts of oleic acid. The addition of Tween 80 did not improve growth on media containing cholesterol. 


\section{DISCUSSION}

The evidence presented here suggests that cholesterol is an essential medium component for growing certain organisms of the pleuropneumonia group isolated from animals. Growth was obtained on a basal medium to which cholesterol had been added as a finely dispersed suspension. For satisfactory growth it was necessary to incorporate also in the medium starch, bovine albumin or the acetone-insoluble fraction of egg-yolk (AIL), previously described. No growth resulted from the addition to the medium of any of these latter substances, alone or in combination, in the absence of cholesterol. For maximal growth enough cholesterol had to be added to give a concentration of at least $0.01 \mathrm{mg}$. $/ \mathrm{ml}$. When horse serum was used for enrichment, $2.5 \%(\mathrm{v} / \mathrm{v})$ was the least concentration giving good growth. Mayer \& Schaeffer (quoted by Bloor, 1943) found horse serum to contain $0.83 \mathrm{mg}$. cholesterol $/ \mathrm{ml}$. About $70 \%$ of this cholesterol was present as esters of fatty acids (Bloor, 1943). Thus the addition of $2.5 \%$ horse serum to the medium could provide enough free cholesterol to give a concentration of $c .0 .006 \mathrm{mg}$. $/ \mathrm{ml}$., which is in close agreement with the concentration found to be required when a suspension of cholesterol was used.

Cholesterol has been found necessary for the growth and development of certain insects; for instance, McKinnis (1947) showed that cholesterol or another sterol was required for the development of larvae of the black carpet beetle. Cailleau (1937), in a study of the growth requirements of Trichomonas, found cholesterol to be essential for the growth of $T$. columbae; certain other sterols and the esters of cholesterol were also effective. Griffin \& McCartin (1949) showed that cholesterol or its esters with oleic and palmitic acids could replace serum in media used for growing Entamoeba histolytica; a concentration of $0.09 \mathrm{mg} . / \mathrm{ml}$. was effective. Certain bacteria, such as soil bacteria of the genus Proactinomyces (Turfitt, 1947) and Mycobacterium smegmatis (Sobel \& Plaut, 1949) have been shown to oxidize and decompose cholesterol, growth taking place when cholesterol was the sole source of carbon. Lwoff (1947) investigated the factor in serum which permitted growth of Moraxella lacunata and Neisseria gonorrhoeae. The organisms grew poorly, or not at all, in plain broth, unless it was enriched with serum. Good growth followed the addition to the broth of a soluble ester of cholesterol instead of serum, but equally good growth was obtained simply by diluting the broth. Lwoff concluded that cholesterol was not a growth factor in the strict sense; it acted by neutralizing inhibitory substances in the broth, which were probably fatty acids. Thus, although cholesterol is essential for the growth of certain insects and Protozoa, it is not known to be an essential nutrient for any bacteria.

The importance of cholesterol in the cultivation of pleuropneumonia-like organisms was first suggested by the observations of Partridge \& Klieneberger (1941). They showed that oily globules, found in colonies of the $L 1$ organism, consisted largely of free cholesterol. The amount of cholesterol, associated with the organisms in the culture, was comparatively large; the total lipid which could be extracted from the organisms was about $40 \%$ of their dry weight and 
about $40 \%$ of this was cholesterol. It did not appear that this cholesterol was synthesized by the organism, for there was shown to be a decrease of cholesterol in the medium during growth. The authors failed to obtain growth by adding cholesterol or cholesteryl palmitate instead of serum to the medium. The L 1 organism has not yet been included among the strains which we have tested on media containing cholesterol and albumin, or cholesterol and AIL. Observations on the growth requirements of this organism will be of interest, for it is typical of those strains which are the pleuropneumonia-like forms of bacteria. A comparison of the growth requirements of the corresponding bacillary and pleuropneumonia-like forms may assist in elucidating the relationship of the one to the other. It is to be noted that all pleuropneumonia-like forms which have been isolated from Gram-negative bacilli have needed media enriched with serum, even though the bacillary form did not; on the other hand, pleuropneumonia-like forms, isolated from Gram-positive bacilli, have not needed serum (Dienes, 1950).

Two other compounds, cholestanol and stigmasterol, were as effective as cholesterol in promoting growth, while ergosterol and coprosterol appeared to be inactive (although the tests of these latter compounds may have been unsatisfactory). Examination of a larger number of sterols would be necessary before an attempt could be made to correlate activity with chemical structure. Cholesterol esters of acetic, stearic and oleic acids were inactive. Esterification, however, did not necessarily abolish the activity of cholesterol, because growth was obtained with cholesteryl hydrogen phthalate. The action of this ester may have been facilitated by its water solubility.

Growth could seldom be obtained by adding cholesterol alone to the basal medium; it was necessary to incorporate with it certain substances, namely starch, bovine albumin or AIL. It seems likely that their action, at least in part, was to bind fatty acids so that they were not present free in the medium in toxic amounts; oleic acid in excessive concentrations was shown to be inhibitory. Cholesterol itself forms complexes with fatty acids. However, this ability cannot explain its action in promoting growth, because it could not be replaced by other substances such as bovine albumin, which neutralize the inhibitory effects of fatty acids.

Of the eight strains tested two, namely strain C48 and the strain of Asterococcus bovis, could not be grown regularly even with cholesterol and AIL. In the early experiments there appeared to be something in AIL which was inhibitory for strain C48. Later, after a further period of subculture, there was some growth of this strain on media containing cholesterol and AIL. Growth of $\boldsymbol{A}$. bovis was erratic; it grew in some experiments but not in others on media with cholesterol and albumin or cholesterol and AIL. Also, unlike the other strains it did not grow well on media enriched with egg-yolk instead of serum. Thus strains appeared to vary in the ease with which they could be grown; of those studied $A$. bovis and strain C 48 were the most exacting in their requirements. It would seem that the conditions for the growth of organisms of this group are highly complex and that all the factors necessary have not yet been elucidated. 
We wish to express our gratitude to Prof. B. C. J. G. Knight for his encouragement and many helpful suggestions, to Dr S. Wilkinson for preparing fractions of phospholipids, and to Prof. G. A. D. Haslewood for samples of sterols.

\section{REFERENCES}

Bloon, W. R. (1943). Biochemistry of the Fatty Acids and their Compounds, the Lipids. New York: Reinhold Publishing Corporation.

Cailleau, R. (1937). La nutrition des flagellés tétramitidés. Les sterols, facteurs de croissance pour les trichomonades. Ann. Inst. Pasteur, 59, 293.

Davis, B. D. \& Dubos, R. J. (1947). The binding of fatty acids by serum albumin, a protective growth factor in bacteriological media. J. exp. Med. 86, 215.

Dienes, L. (1950). Isolation of L type cultures from Clostridia. Proc. Soc. exp. Biol., N.Y., 75, 412 .

Edward, D. G. FF. (1947). A selective medium for pleuropneumonia-like organisms. J. gen. Microbiol. 1, 238.

Edward, D. G. FF. (1950). An investigation of the biological properties of organisms of the pleuropneumonia group, with suggestions regarding the identification of strains. J. gen. Microbiol. 4, 311.

Edward, D. G. FF. \& Fitzgerald, W. A. (1951). The isolation of organisms of the pleuropneumonia group from dogs. J. gen. Microbiol. 5, 566.

Griffin, A. M. \& MCCARtin, W. G. (1949). Sterols and fatty acids in the nutrition of entozoic amoebae in cultures. Proc. Soc. exp. Biol., N.Y., 72, 645.

Hartuey, P. (1925). Observations on the role of the ether-soluble constituents of serum in certain serological reactions. Brit. J. exp. Path. 6, 180.

Haslewood, G. A. D. (1944). Cholesterol metabolism in the animal body. Nature, Lond., 154, 29.

Lamblaw, P. P. \& Elford, W. J. (1936). A new group of filtrable organisms. Proc. roy. Soc. B, 120, 292.

Lwoff, A. (1947). Sur le role du serum dans le développement de Moraxella lacunata et du Neisseria gonnorrhae. Ann. Inst. Pasteur, 73, 735.

McKinnis, H. jun. (1947). The growth-promoting activity of cholesterol and related compounds in black carpet beetle larvae. J. biol. Chem. 167, 645 .

Partridge, S. M. \& KuIeneberger, E. (1941). Isolation of cholesterol from the oily droplets found in association with the L1 organism separated from Streptobacillus moniliformis. J. Path. Bact. 52, 219.

Pollock, M. R. (1949). The effects of long-chain fatty acids on the growth of Haemophilus pertussis and other organisms. Symposia of the Society for Experimental Biology, No. 3, p. 193. Cambridge University Press.

Sarin, A. B. (1941). The filtrable micro-organisms of the pleuropneumonia group. Bact. Rev. 5, 1.

Sobel, H. \& Plaut, A. (1949). The assimilation of cholesterol by Mycobacterium smegmatis. J. Bact. 57, 377 .

TURFITT, G. E. (1947). Microbiological agencies in the degradation of steroids. II. Steroid utilization by the microflora of soils. J. Bact. 54, 557. 